\title{
Reverse Shoulder Arthroplasty for Proximal Humerus Fracture
}

\author{
Brandon J. Kelly ${ }^{1} \cdot$ Chad M. Myeroff ${ }^{1,2,3}$
}

Published online: 12 April 2020

(C) Springer Science+Business Media, LLC, part of Springer Nature 2020

\begin{abstract}
Purpose of Review The purpose of this review is to examine trends, outcomes, and principles in treatment of proximal humerus fractures in the elderly with a critical focus on reverse shoulder arthroplasty as a developing treatment option.

Recent Findings Recent literature shows an increase in reverse shoulder arthroplasty and a decrease in hemiarthroplasty performed for proximal humerus fractures. More predictable outcomes and lower revision rates are seen in older individuals treated primarily or secondarily with reverse shoulder arthroplasty compared to those treated with hemiarthroplasty.

Summary We report current and historical treatments, outcomes, and principles in reverse shoulder arthroplasty for treatment of complex, displaced proximal humerus fractures in older individuals ( $\geq 65$ years old).
\end{abstract}

Keywords Reverse shoulder arthroplasty $\cdot$ Proximal humerus fracture $\cdot$ Fragility fracture $\cdot$ Fracture sequelae

\section{Introduction}

Proximal humerus fractures make up 5\% of all fractures and are the third most common fracture in patients who are 65 years and older [1]. These fractures predominantly occur in women $(70 \%)$ and occur at the highest frequency from ages 80 to 84 years old [2-8]. Initial projections suggested a potential three-fold increase in the rate of proximal humerus fractures by 2030 [7], but newer data showed a flat incidence from 2006 to 2012 and subsequent projections are tempered [9].

While younger patients are typically victim to high-energy trauma, the predominant injury mechanism overall is a fall from standing height [10]. These fragility fractures, occurring in low energy mechanisms, are a sentinel marker of poor bone health and general health decline. At 1-year post-injury, there is a $10 \%$ mortality rate for proximal humerus fracture regardless of treatment [11]. Patients who do not live alone, who do

This article is part of the Topical Collection on Reverse Shoulder Arthroplasty

Chad M. Myeroff

myero316@umn.edu

1 Department of Orthopedic Surgery, University of Minnesota, Minneapolis, MN, USA

2 Regions Hospital, Saint Paul, Minnesota, 640 Jackson St, MS 11503L, Saint Paul, MN 55101, USA

3 TRIA Orthopaedic Center, Woodbury, MN, USA not participate in recreational activities, and who are not independent of their activities of daily life are at significantly higher risk for a poor outcome [3].

Medical, functional, and fracture-specific complexities make treatment of these injuries challenging. Regardless, $67-85 \%$ of proximal humerus fractures are treated nonoperatively $[1,5]$. But as technology and patient demand evolve, the rate of surgical intervention is increasing $[1,2]$. The use of open reduction internal fixation (ORIF) has remained stable, hemiarthroplasty has decreased, and reverse shoulder arthroplasty (RSA) has increased $[1,5,8,9,12 \bullet, 13$, 14]. Reports on the utilization of RSA for proximal humerus fractures are variable, but all show an increase over the past decade ranging from $26 \%$ in 2011 to $67.4 \%$ in 2015 [1, 5, 8, $12 \cdot, 14,15]$. Surgical treatment choice for proximal humerus fracture is highly dependent on patient anatomy, fracture pattern, pre-injury functional status, medical comorbidities, and surgeon skill level and bias.

\section{Nonoperative Treatment}

Nonoperative management of displaced 3- and 4-part proximal humerus fractures uniformly leads to low functional scores and loss of range of motion in active, independent individuals $[16,17]$. Increasing fracture fragments and magnitude of displacement predicts worse outcomes, functional scores, and range of motion limitations with nonoperative treatment [18]. However, proximal humerus fractures with 
more simple patterns, those that are minimally displaced or that occur in the low-demand patient are often amenable to closed treatment. Acceptable functional outcomes have been observed in patients with translated 2-part proximal humerus fractures with average displacement of $>66 \%$ [19], valgus impacted 1- and 2-part fractures [20, 21], and fractures with $<5 \mathrm{~mm}$ displacement of the greater tuberosity [22]. In such cases, return to adequate function can be achieved with close observation for 3-4 weeks, followed by progressive passive range of motion as the fracture consolidates. Recently the PROFHER Trial [23], a multicenter, parallel-group randomized clinical trial comparing surgical and nonsurgical treatment of surgical neck fractures of the proximal humerus and its subsequent 5 -year follow-up study [24••] concluded that there were no differences between surgical and non-surgical groups at 2- [23] and 5-year [24••]follow-up intervals. While the study design is certainly a strength, the majority of these fractures were not the displaced 3- and 4-part fractures $(50 \%$ were 2-part) that come to mind when considering surgical intervention. Additionally, the surgical procedures varied including ORIF, intramedullary nails, hemiarthroplasty, and "other" treatments. Finally, there were 1000 patients out of 1250 patients that were excluded from final analysis ( 80 of which were "obviously operative"), which introduces the possibility of significant bias. Active patients with highly displaced fractures and surgeons continue to look for better options than a sling in returning to optimal function.

\section{Proximal Humerus Fracture Surgical Treatment}

\section{Historical}

Proximal humerus fractures have challenged clinicians for many years [25]. Treatment in the nineteenth century was hallmarked by the Hippocratic method of reduction followed by bandaging and delayed splinting. In the twentieth century, further surgical and anesthetic advancements sparked attempts at ORIF [26]. The first documented shoulder arthroplasty was reportedly performed by Jules Emile Pean in 1893 for tuberculosis [27]. However, Dr. Charles Neer II popularized and revolutionized the idea of shoulder arthroplasty and humeral head replacement in 1955 to mitigate the risk of avascular necrosis or flail shoulder associated with open reduction and excision of proximal humerus fractures [28]. His classification of proximal humerus fractures followed in 1970 as well as his criteria for evaluation of treatment results [29]. The follow-up report on treatment of 3- and 4-part proximal humerus fractures treated with closed reduction, ORIF, and hemiarthroplasty showed that closed treatment was inadequate in active patients, ORIF was more effective in 3-part fractures, and hemiarthroplasty was superior in the 4-part group [30]. However, results were only satisfactory and Dr. Neer had "limited expectations" for the final limb function, ultimately describing the treatment as imperfect [30]. In years to follow, Dr. Neer's hypothesis was tested and expounded upon in an attempt to improve outcomes for patients with proximal humerus fractures.

\section{ORIF with Standard Implants}

In the 1980s and 1990s ORIF with a variety of constructs like non-locking plates, wires, and pins produced variable results for 3- and 4-part proximal humerus fractures. All techniques and implants had marginally acceptable complication rates and outcomes [31-34]. While percutaneous pinning has merits in young patients with simple fractures and good bone quality, it is inadequate fixation in osteoporotic bone.

\section{ORIF with Locked Plates}

The introduction of pre-contoured locking plates, in particular the proximal humerus internal locking system (PHILOS), demonstrated biomechanical promise with good initial functional outcomes. However, longer-term follow-up revealed frequent complications with high rates of screw perforation into the glenohumeral joint and screw cut-out [35-42]. Brunner et al. in a 2009 prospective multicenter analysis of this treatment found a $9 \%$ implant-related complication rate and a $35 \%$ overall complication rate at 1 -year follow-up using the PHILOS system. The most common implant complications were primary screw perforation $(14 \%)$ and secondary screw perforation (8\%) [35]. Additionally, Owsley and Gorczyca observed a 36\% radiographic complication rate, including 23\% intra-articular screw displacement and 25\% varus displacement $>10^{\circ}$. Patients older than 60 years of age were significantly more at risk for these complications $(57 \%$ vs. $22 \%, p=0.0015)$ [41].

More important than the technology itself, improvements have been made in the understanding of how and when to best perform ORIF. We have learned important predictors of success include restoration or maintenance of the medial calcar [43], avoiding varus alignment [44], and less aggressive proximal screw fixation [45]. Although not biomechanically shown to be beneficial, rotator cuff sutures have become the standard among fracture surgeons for fragment mobilization, provisional reduction, and final construct incorporation [46]. More recent analyses of proximal humerus fractures treated with newer locking plates show less complications and improved outcomes. In the most recent 3 years studied (20112013), there were significantly less failures due to loss of fixation $(5.7 \%$ vs. $12.8 \%, p=0.006)$ and overall revision rate ( $3.2 \%$ vs. $15.3 \%, p=0.00004$ ) compared to the first 3 years of the study (2002-2004) [47]. Improved results with ORIF in recent years are likely multifactorial. Improved understanding of patient prognostic factors, refined surgical techniques, and surgeon experience have been critical. While locking 
technology has advanced little since the PHILOS plate, our implementation of it has improved. In addition, advances in arthroplasty technology provide the surgeon alternatives in fractures that would otherwise have pushed the indications for locking plate technology in previous decades.

\section{Hemiarthroplasty}

Popularized by Dr. Neer, the hemiarthroplasty became a viable treatment option for 3-part, 4-part, and head-splitting proximal humerus fractures. Humeral head replacement was an alternative to acute humeral head excision, glenohumeral arthrodesis, or for the prevention or treatment of osteonecrosis [28]. Much of Dr. Neer's work focused on stratifying risk of osteonecrosis based on fracture severity. His surgical recommendations hinged on preventing this complication which he reported as high as $75 \%$ in 4-part fractures treated with ORIF [29]. In the wake of this, Hertel et al. went on to identify risk factors of osteonecrosis including (1) short medial calcar extension $(<8 \mathrm{~mm})$, (2) disrupted periosteal hinge, and (3) anatomic neck fracture [48]. A later interrogation of these factors showed that while one risk factor does not increase the risk, all three factors, and more importantly a poor reduction were linked to the risk of osteonecrosis, but this complication only occurred in $3.7 \%$ of patients [49]. While osteonecrosis may occur after a proximal humerus fracture, contemporary studies show the reported rate in nonoperative treatments is $2 \%$ overall [21], and only $7.9 \%$ in operatively treated 3- and 4-part factures [42]. Further, the rate of symptomatic osteonecrosis in nonoperatively treated 3- and 4-part fractures is even lower, at $1.6 \%$ [50]. With the variety and success of surgical options today, the surgical approach and decision making for complex proximal humerus fractures should predicate on the surgeon's ability to anatomically reconstruct and maintain reduction rather than on likelihood of head viability.

Hemiarthroplasty is largely marginalized except for in the rare, unreconstructible fractures in active, young adult patients. It is the senior author's experience that a hemiarthroplasty for fracture should be a no more frequent than about once a year for even a busy shoulder surgeon. While significant initial pain relief is reported as a positive outcome in most hemiarthroplasty studies, the functional outcomes and range of motion results are highly variable and in many studies are quite poor $[51,52]$. Boons et al. in a randomized controlled trial from 2012 detected no significant differences in older individuals treated nonoperatively and those treated with hemiarthroplasty for 4-part fractures [53]. Recovery and function after hemiarthroplasty are notably worse in older ( $>55$ years old) patients [54, 55].

Failure and poor outcomes are associated with prosthesis height overstuffing or humeral length increase $>10 \mathrm{~mm}$, humeral head retroversion $>40^{\circ}$, low greater tuberosity positioning (10 $\mathrm{mm}$ inferior to the tangent line of the head), or high greater tuberosity positioning $(5 \mathrm{~mm}$ superior to the tangent line of the head) [56]. Successful hemiarthroplasty outcome is dependent on anatomic tuberosity healing and head size and height, avoiding tuberosity resorption, and maintaining rotator cuff integrity [57••]. Indications for hemiarthroplasty are narrow. The procedure is technically demanding, and the construct relies heavily on the unpredictable healing of the tuberosities. Hemiarthroplasty is best reserved for the young patient with an unreconstructible proximal humerus fracture.

\section{Reverse Shoulder Arthroplasty}

Reverse shoulder arthroplasty initially was introduced as a solution for rotator cuff arthropathy. Initial prostheses failed, but Dr. Grammont revolutionized the design strategy in 1985 using the following principles: (1) inherent stability of prosthesis, (2) convex weightbearing portion, concave support portion, (3) the center of the sphere must be at or medial to the glenoid neck, and (4) medial and inferior center of rotation. While design details evolve, Dr. Grammont's principles of RSA still guide implant development and surgical technique today [27].

In November 2003, the food and drug administration (FDA) approved the use of RSA in the USA. From 2003 to 2004, there was a large initial increase in shoulder arthroplasty and a subsequent steady annual increase thereafter [13]. As RSA volume increased, so did the body of literature and evidence to support its use for proximal humerus fractures [58-65]. The consistent challenges, failures, and variable outcomes with nonoperative treatment, ORIF, and hemiarthroplasty for proximal humerus fractures, particularly in elderly individuals, led to a significantly increased use of RSA for proximal humerus fractures mainly due to its independence of rotator cuff (tuberosity) healing.

The most commonly studied patient population for RSA is older adults ( $\geq 65$ years old) with 3-part, 4-part, or headsplitting fractures of the proximal humerus. Initial results of RSA for acute proximal humerus fracture showed satisfactory mobility and functional outcomes, despite frequent radiographic migration of the tuberosities [63]. Early studies concluded that RSA for proximal humerus fracture provided pain relief, good functional outcome scores, and functional range of motion [63-65].

Surgical techniques, implant technology, and patient selection continue to be refined and have led to improved RSA outcomes for proximal humerus fractures. A 2016 retrospective review with mean 35-month follow-up of 52 patients, 5989 years old, with 3- and 4-part proximal humerus fractures treated with RSA, reported mean postoperative constant score of 62 (range 16-69) [59]. Wright et al. in a prospective case series with 2.5-year follow-up of 30 patients, $>59$ years old, with 3- and 4-part proximal humerus fractures, reported mean active forward elevation to $130^{\circ}$ postoperatively and $97 \%$ 
stable radiographic appearance rate [60••]. In a quality of life analysis, Wolfensperger et al. reported that in 33 highly independent patients, $84 \%$ were back to previous levels of independence at 6 months postoperatively and $91 \%$ at 1 -year postoperatively after RSA [62・•] (please see Table 1 for summary of RSA outcome study results).

Despite the reliable results of RSA, outcomes are far from normal, and nonoperative management should be strongly considered in very low demand, medically unwell, or those strongly opposed to surgery. Roberson et al. in 2017 retrospectively compared patients who were recommended RSA and refused to those who elected to undergo RSA. While the study is confounded with a predominant selection bias, they found no significant functional, range of motion, or other clinical differences between RSA and nonoperative management at 1-year follow-up in 3- and 4- part proximal humerus fractures [66]. We counsel our patients that the goal is to achieve $80 \%$ for "normal" shoulder function that is painless and able to achieve self-care. We tell patients preoperatively that forward elevation can more predictably be achieved and rotation is less predictable. Most patients are able to reach the back of their head and perineum but unclipping a bra is unlikely.

RSA is also used as a salvage procedure after failure of closed treatment, ORIF, or hemiarthroplasty for proximal humerus fracture. Compared to primary RSA, these indications result in higher complication rates, higher revision rates, and marginally lower functional outcomes (please see Table 2 for summary of RSA as secondary procedure outcomes study results). Dezfuli et al. in a 2016 retrospective review identified that acute RSA outperformed RSA for malunion, nonunion, and conversion from ORIF or hemiarthroplasty. Additionally, RSA for malunion or nonunion outperformed revision from hemiarthroplasty [58]. Sebastia-Forcada et al. in a 2017 matched case-control study of patients who underwent primary RSA for fracture or secondary RSA after ORIF failure found that both groups improved significantly from preoperative state, but functional outcomes were significantly better in the primary RSA group [67••]. Shannon et al. in a 2016 retrospective review comparing primary RSA and RSA after failed ORIF found no significant differences in functional outcomes, but an increased complication rate in secondary RSA [61]. Finally, a 2019 systematic review and metaanalysis of acute versus delayed RSA for proximal humerus fractures by Torchia et al. found no difference in clinical outcome scores, forward flexion, or all cause-reoperation rate when comparing primary or secondary RSA for proximal humerus fracture [69*0]. While RSA has good results as a salvage treatment, functional outcomes and complication rates are better in the primary setting.

\section{Reverse Shoulder Arthroplasty Versus Hemiarthroplasty}

Despite the drastic rise in rate of RSA and drop in hemiarthroplasty for proximal humerus fractures, research and comparisons of the two surgical treatments continue [1, 12•]. In a 2019 systematic review and meta-analysis, Austin et al. found that in 421 RSA and 492 hemiarthroplasties, RSA significantly outperformed hemiarthroplasty for postoperative pain scores, functional outcomes scores, and forward flexion, whereas hemiarthroplasty had a significantly higher risk of reoperation [70••]. Shukla et al. in 2016 performed a metaanalysis and found forward flexion, abduction, tuberosity healing, and functional scores were all significantly better for RSA postoperatively, while external rotation was better for hemiarthroplasty [71]. Ferrel et al. performed a systematic review in 2014 and found that RSA patients have better forward flexion, but hemiarthroplasty had better external rotation. Additionally, there were complication rates of $9.6 \%$ for

Table 1 Reverse shoulder arthroplasty for proximal humerus fracture results

\begin{tabular}{|c|c|c|c|c|c|c|c|c|c|}
\hline Author & Year & $\begin{array}{l}\text { Mean } \\
\text { Age } \\
\text { (years) }\end{array}$ & $\begin{array}{l}\text { Mean } \\
\text { follow-up }\end{array}$ & $\begin{array}{l}\text { No. of } \\
\text { patients }\end{array}$ & $\begin{array}{l}\text { Mean primary } \\
\text { functional outcome } \\
\text { score (range) }\end{array}$ & $\begin{array}{l}\text { Mean active } \\
\text { forward flexion } \\
\text { (degrees) }\end{array}$ & $\begin{array}{l}\text { Mean active } \\
\text { external rotation } \\
\text { (degrees) }\end{array}$ & $\begin{array}{l}\text { Complication } \\
\text { rate }\end{array}$ & $\begin{array}{l}\text { Revision } \\
\text { rate }\end{array}$ \\
\hline $\begin{array}{l}\text { Bufquin et al. } \\
\text { [63] }\end{array}$ & 2007 & 78 & 22 months & 43 & CS 44 (16-69) & $97(35-160)$ & $8(-40-40)$ & $27.9 \%$ & NA \\
\hline $\begin{array}{l}\text { Grubhofer } \\
\text { et al. [59] }\end{array}$ & 2016 & 77 & 35 months & 73 & CS 62 (21-83) & $118(40-165)$ & $18(0-65)$ & NA & $5.4 \%$ \\
\hline $\begin{array}{l}\text { Wright et al. } \\
{[60]}\end{array}$ & 2019 & 71 & 56 months & 21 & ASES $82.0 \pm 13.5$ & $130 \pm 31$ & $32 \pm 18$ & $14.3 \%$ & $4.7 \%$ \\
\hline $\begin{array}{l}\text { Klein et al. } \\
\text { [64] }\end{array}$ & 2008 & 75 & 33 months & 20 & CS 68 (47-98) & $123(60-175)$ & $25(10-35)$ & $15 \%$ & $10 \%$ \\
\hline $\begin{array}{l}\text { Lenarz et al. } \\
{[65]}\end{array}$ & 2011 & 76 & 23 months & 30 & ASES 78 (36-98) & $139(90-180)$ & $27(0-45)$ & $10 \%$ & $0 \%$ \\
\hline $\begin{array}{l}\text { Wolfensperger } \\
\text { et al. [62] }\end{array}$ & 2017 & 80 & 12 months & 33 & CS 71 (46-94) & NA & NA & $9 \%$ & $0 \%$ \\
\hline
\end{tabular}

$C S$, constant score; ASES, American Shoulder and Elbow Surgeons Score; NA, not available 
Table 2 Primary versus secondary reverse shoulder arthroplasty for proximal humerus fracture

\begin{tabular}{|c|c|c|c|c|c|c|c|c|c|c|}
\hline Author & Year & $\begin{array}{l}1^{\circ} \\
\text { or } \\
2^{\circ}\end{array}$ & $\begin{array}{l}\text { Mean } \\
\text { age } \\
\text { (years) }\end{array}$ & $\begin{array}{l}\text { Mean } \\
\text { follow-up }\end{array}$ & $\begin{array}{l}\text { No. of } \\
\text { patients }\end{array}$ & $\begin{array}{l}\text { Mean primary } \\
\text { functional outcome } \\
\text { score (range) }\end{array}$ & $\begin{array}{l}\text { Mean active } \\
\text { forward flexion } \\
\text { (degrees) }\end{array}$ & $\begin{array}{l}\text { Mean active } \\
\text { external rotation } \\
\text { (degrees) }\end{array}$ & $\begin{array}{l}\text { Complication } \\
\text { rate }\end{array}$ & $\begin{array}{l}\text { Revision } \\
\text { rate }\end{array}$ \\
\hline \multirow[t]{2}{*}{ Dezfuli et al. [58] } & \multirow[t]{2}{*}{2016} & $1^{\circ}$ & 78 & 34 Months & 13 & CS 67 & 113 & 24 & $7.6 \%$ & $7.6 \%$ \\
\hline & & $2^{\circ}$ & 68 & 32 Months & 36 & CS 54 & 99 & 10 & $13.9 \%$ & $13.9 \%$ \\
\hline \multirow{2}{*}{$\begin{array}{l}\text { Shannon et al. } \\
\text { [61] }\end{array}$} & \multirow[t]{2}{*}{2016} & $1^{\circ}$ & 75 & 36 Months & 18 & ASES 70.6 & 133 & 36 & $5 \%$ & $0 \%$ \\
\hline & & $2^{\circ}$ & 70 & 24 Months & 26 & ASES 64.6 & 130 & 42 & $8 \%$ & $0 \%$ \\
\hline \multirow{2}{*}{$\begin{array}{l}\text { Sebastia-Forcada } \\
\text { et al. [67] }\end{array}$} & \multirow[t]{2}{*}{2017} & $1^{\circ}$ & 75 & 38 Months & 30 & CS 60.4 & 127 & 4.9 & $3.3 \%$ & $3.3 \%$ \\
\hline & & $2^{\circ}$ & 73 & 38 Months & 30 & CS 55.5 & 114 & 4.1 & $20 \%$ & $13.3 \%$ \\
\hline \multirow[t]{2}{*}{ Seidl et al. [68] } & \multirow[t]{2}{*}{2016} & $1^{\circ}$ & 77 & 45 Months & 15 & ASES 77 & 129 & 29 & $0 \%$ & $0 \%$ \\
\hline & & $2^{\circ}$ & 71 & 45 Months & 43 & ASES 72.4 & 118 & 13 & $22 \%$ & $4.7 \%$ \\
\hline
\end{tabular}

$C S$, constant score; ASES, American Shoulder and Elbow Surgeons Score

$1^{\circ}$ is acute RSA for proximal humerus fracture; $2^{\circ}$ is delayed RSA (malunion, nonunion, hemiarthroplasty, ORIF)

RSA and $4.1 \%$ for hemiarthroplasty, but reoperation rate for RSA was $1 \%$ and for hemiarthroplasty was $4 \%$ [72]. Gallinet et al. in 2018 performed a systematic review and metaanalysis and found that RSA patients had better clinical outcome scores and forward flexion, while hemiarthroplasty patients had better internal and external rotation. Additionally, there were higher complication and reoperation rates noted in RSA patients, but higher revision rates in hemiarthroplasty patients [73••]. Namdari et al. in a systematic review in 2013 found that RSA had 4.0 times greater odds of postoperative complications but concluded that many of those were radiographic without clinical consequence [74] (please see Table 3 for summary of RSA and hemiarthroplasty outcome study results).

Extensive comparison of RSA and hemiarthroplasty in older adults with 3-part, 4-part, and head-splitting proximal humerus fractures shows that more favorable and reliable functional outcomes are seen in patients with RSA. While complication rate comparison is variable, revision rates are significantly lower in RSA patients. Additionally, the importance of purely radiographic complications is unknown [74]. Unlike the hemiarthroplasty, successful outcome with RSA is not fully dependent on tuberosity healing and rotator cuff integrity $[57 \bullet \bullet]$. However, tuberosity healing and anatomic tuberosity healing may improve constraint, and shoulder range of motion for patients with $\operatorname{RSA}[81 \bullet, 82 \bullet, 83 \bullet, 84 \bullet]$.

\section{Reverse Shoulder Arthroplasty Versus Open Reduction Internal Fixation}

Patients who are treated with ORIF have fewer short-term complications than those treated with RSA or hemiarthroplasty

Table 3 Reverse shoulder arthroplasty versus hemiarthroplasty for proximal humerus fracture

\begin{tabular}{|c|c|c|c|c|c|c|c|c|c|c|}
\hline Author & Year & $\begin{array}{l}\text { RSA } \\
\text { vs. } \\
\text { HA }\end{array}$ & $\begin{array}{l}\text { Mean } \\
\text { age } \\
\text { (years) }\end{array}$ & $\begin{array}{l}\text { Mean } \\
\text { follow-up }\end{array}$ & $\begin{array}{l}\text { No. of } \\
\text { Patients }\end{array}$ & $\begin{array}{l}\text { Mean primary } \\
\text { functional outcome } \\
\text { score (range) }\end{array}$ & $\begin{array}{l}\text { Mean active } \\
\text { forward flexion } \\
\text { (degrees) }\end{array}$ & $\begin{array}{l}\text { Mean active } \\
\text { external rotation } \\
\text { (degrees) }\end{array}$ & $\begin{array}{l}\text { Complication } \\
\text { rate }\end{array}$ & $\begin{array}{l}\text { Revision } \\
\text { rate }\end{array}$ \\
\hline \multirow{2}{*}{$\begin{array}{l}\text { Bonnevialle } \\
\text { et al. [75] }\end{array}$} & \multirow[t]{2}{*}{2016} & RSA & 78 & 39 months & 40 & CS 57 & 130 & 23 & $10 \%$ & $0 \%$ \\
\hline & & HA & 67 & 39 months & 57 & CS 54 & 112 & 28 & $24 \%$ & $1.7 \%$ \\
\hline \multirow{2}{*}{$\begin{array}{l}\text { Boyle et al. } \\
\text { [76] }\end{array}$} & \multirow[t]{2}{*}{2013} & RSA & 80 & 60 months & 55 & Oxford 41.5 & Not included & Not included & Not included & $1.7 \%$ \\
\hline & & HA & 72 & 60 months & 313 & Oxford 32.3 & Not included & Not included & Not included & $1.1 \%$ \\
\hline \multirow{2}{*}{$\begin{array}{l}\text { Chalmers } \\
\text { et al. [77] }\end{array}$} & \multirow[t]{2}{*}{2014} & RSA & 77 & 14 months & 9 & ASES 80 & 133 & 41 & $11 \%$ & $0 \%$ \\
\hline & & HA & 72 & 14 months & 9 & ASES 66 & 106 & 28 & $22 \%$ & $0 \%$ \\
\hline \multirow{2}{*}{$\begin{array}{c}\text { Cuff et al. } \\
{[78]}\end{array}$} & \multirow[t]{2}{*}{2013} & RSA & 74 & 24 months & 24 & ASES 77 & 139 & 24 & $9 \%$ & $0 \%$ \\
\hline & & HA & 74 & 24 months & 23 & ASES 62 & 100 & 25 & $8 \%$ & $13 \%$ \\
\hline \multirow{2}{*}{$\begin{array}{l}\text { Garrigues } \\
\text { et al. [79] }\end{array}$} & \multirow[t]{2}{*}{2012} & RSA & 75 & 42 months & 11 & ASES 81.1 & 121 & 34 & $9 \%$ & $0 \%$ \\
\hline & & HA & 75 & 42 months & 12 & ASES 47.4 & 91 & 31 & $33 \%$ & $25 \%$ \\
\hline \multirow{2}{*}{$\begin{array}{l}\text { Van der } \\
\text { Merwe } \\
\text { et al. [80] }\end{array}$} & \multirow[t]{2}{*}{2017} & RSA & 78 & 60 months & 218 & Oxford 37.62 & Not included & Not included & Not included & $0.58 \%$ \\
\hline & & HA & 72 & 60 months & 427 & Oxford 32.74 & Not included & Not included & Not included & $1.16 \%$ \\
\hline
\end{tabular}

CS, constant score; ASES, American Shoulder and Elbow Surgeons Score, Oxford, Oxford Shoulder Score 
for proximal humerus fractures [85]. Additionally, patients treated with RSA have a higher 90-day readmission rate than those who have ORIF [86]. It is intuitive that patients undergoing RSA have both more medical and fracture complexity; and inability to stratify by patient comorbidities, fracture pattern, and classification is a limitation of these large database studies. In 2014, Chalmers et al. retrospectively compared ORIF and RSA for proximal humerus fracture and found no significant functional outcome differences, but significantly more RSA patients achieved $>90^{\circ}$ forward flexion than ORIF patients [77]. In a 2015 systematic review of 92 studies including 45,000 patients comparing surgical management of complex proximal humerus fractures, Gupta et al. reported a $15 \%$ complication rate for ORIF with a $12.7 \%$ reoperation rate, and a $18.9 \%$ complication rate for RSA with a 5.0\% reoperation rate [87]. Patients undergoing RSA have increased readmission rates and short-term complication rates compared to those undergoing ORIF, but this may be a function of selection bias, patient age, and medical comorbidities for the selected treatments. RSA appears to be more durable with lower revision rates.

\section{Complications}

In a 2019 multicenter retrospective review of 898 patients with proximal humerus fractures treated with RSA, there was a $12.5 \%$ overall complication rate, a $5 \%$ revision rate, and a $6 \%$ mortality rate at 1 year postoperatively. Reasons for revision were instability $(2.5 \%)$, aseptic loosening of humeral component $(1.5 \%)$, peripheral nerve injury $(1.3 \%)$, infection $(1.3 \%)$, aseptic loosening of glenoid component $(1.2 \%)$, periprosthetic fracture $(0.9 \%)$, complex regional pain syndrome $(0.7 \%)$, and medical complications (3.1\%) [88]. In another 2019 retrospective review of RSA for proximal humerus fractures, there was a $22 \%$ complication rate and a $5.1 \%$ revision rate. Instability was the most common complication at 33\%, followed by scapular notching $11.9 \%$ [89•]. Complication rates are variably reported and dependent on classification and reporting of the complications. However, revision rate appears consistent across studies to be around $5 \%$ for RSA [87, 88•, 89•]. Bacle et al. recently published impressive long term implant survival of $93 \%$ at 10 years [90••]. While their study included multiple indications, such results are promising for fracture implications especially in elderly with severe fractures who clearly would benefit from a single, predictable intervention.

\section{How to Approach Reverse Shoulder Arthroplasty for Proximal Humerus Fracture (please see Fig. 1 for initial evaluation and management of proximal humerus fracture patients)}

Reverse Shoulder Arthroplasty in Proximal Humerus Fracture: Indications and Contraindications (please see
Fig. 2 for RSA indications and contraindications in proximal humerus fractures)

Reverse Shoulder Arthroplasty for Proximal Humerus Fracture: Technique (please see Fig. 3 for preoperative planning steps)

At our trauma center, the patient undergoes interscalene regional neuromuscular block in the preoperative area. Once under general anesthesia, the patient is placed in the beach chair position with the head of the bed elevated approximately $45-60^{\circ}$ with a shoulder specific, radiolucent beach chair which must allow adduction, extension, and external rotation of the shoulder (Fig. 7a). Neuromuscular blockade is at the surgeon's discretion but is generally only needed during reduction of an RSA as it can mask signs of dissection in close proximity to the axillary nerve. A large fluoroscopy unit is positioned at the head of the bed (Fig. $7 \mathrm{~g}$ ). The arm is prepped and draped completely with split drapes from the base of the neck distally. We prefer a universal arm positioner for convenience. Tranexamic acid ( $1 \mathrm{~g}$ ) is given prior to incision when not contraindicated to minimize blood loss.

We routinely utilize a deltopectoral incision from the coracoid tip to just past the axillary fold headed toward the lateral epicondyle (Fig. 7b). This is the workhorse approach for anterior shoulder surgery and can be used for fracture, primary arthroplasty, instability, periprosthetic fracture, and revision shoulder surgery. The cephalic vein is mobilized laterally, and the subdeltoid and subacromial space is recreated and a deltoid retractor is placed. We prefer a modified Taylor retractor as it retracts the deltoid without excessive anterior force on the fracture fragments. The clavipectoral fascia is incised just lateral to the conjoint tendon, and bluntly, a plane above and below the conjoint tendon is recreated with care to stay clear of the musculocutaneous and axillary nerves. When present, we use the biceps tendon to orient ourselves to the fracture fragments and alignment. Several no. 2 permanent braided sutures are placed into each rotator cuff tendons at the bone tendon junction starting at the subscapularis and working around to the teres minor (Fig. 7c). The coracohumeral ligament is released from the leading edge of the subscapularis followed by the capsule on its deep surface staying safe from the axillary nerve found running inferior to the tendon. In some implant systems (those which distalize the humeral component), it may be necessary and would be appropriate to release the leading edge of the supraspinatus as it can be antagonistic in reverse shoulder arthroplasty (Fig. 7b) [92]. This suture process not only gains control of the tuberosities but allows the necessary mobilization needed for a tension-free repair. Next, a no. 5 permanent braided suture with a large needle is placed through the teres minor and around the greater tuberosity for later cerclage to the prosthesis. The same is done for the lesser tuberosity with a no. 2 suture. The long head biceps tendon is tenodesed to the pectoralis major tendon with no. 1 dissolvable braided suture prior to tenotomizing from the 


\section{Reverse Shoulder Arthroplasty for Proximal Humerus Fracture: Preoperative Assessment}

- Complete history and physical examination

- Detailed neurovascular examination (note axillary nerve function by setting the deltoid)

○ When function is unclear: repeat exam after several weeks, or Electromyography (EMG) is helpful

- Imaging

- Grashey, Axillary, and Scapular-Y radiographs

- Computed tomography with or without 3-dimensional reconstruction may provide more information if deciding between RSA and ORIF. May identify additional pathology such as a concomitant glenoid fracture.

- Magnetic resonance imaging has little additional benefit

- Fracture Classification

- Neer Classification (29) has low inter and intraobserver reliability (91), but is primary clinical classification system

- Arbeitsgemeinschaft für Osteosynthesefragen (AO) Classification

- Initial Treatment

- Sling or hanging arm cast

○ Non weight bearing affected extremity

Fig. 1 Initial evaluation and management of proximal humerus fractures

supraglenoid tubercle. If needed, an osteotomy of the head is completed, and it is very carefully extracted and set aside for later bone grafting of the tuberosities and impaction grafting of the stem if needed. Care should be taken to remove any fragments avulsed with the capsule.

The glenoid is then exposed with a Fukuda retractor posteriorly, and a Bankart retractor anteriorly on the glenoid neck (Fig. 7d). Following an anterior capsulectomy between the subscapularis and the anteroinferior glenoid rim, the glenoid labrum is excised, and an anterior and inferior capsulotomy is carefully performed along the inferior glenoid with strict attention to avoid injury to the axillary nerve. The glenoid guide pin is placed to allow the baseplate to sit flush with the inferior edge of the glenoid with $0-10^{\circ}$ inferior tilt. We ream conservatively until subchondral bone is exposed with a "smiley face" of bleeding bone only at the inferior edge. The glenoid

\section{a Reverse Shoulder Arthroplasty for Proximal Humerus Fracture: Indications}

- Physiologic age $\geq 65$ years old

- Unreconstructible, highly displaced 3- or 4-part displaced proximal humerus fracture or fracture-dislocations

- Head split proximal humerus fracture

- Failed proximal humerus fracture ORIF

- Symptomatic malunion or nonunion

- Failed hemiarthroplasty

\section{b Reverse Shoulder Arthroplasty for Proximal Humerus Fracture: Contraindications}

- Deltoid deficiency

- Axillary nerve dysfunction

- Insufficient glenoid bone stock

- Active shoulder infection

- Medically unwell

- High demand patient unable to comply with lifestyle modifications

- Charcot joint

Fig. 2 Indications and contraindications for treatment of proximal humerus fracture with reverse shoulder arthroplasty 


\title{
Reverse Shoulder Arthroplasty for Proximal Humerus Fracture: Preoperative Planning
}

\author{
- Anesthesia \\ - Regional interscalene block + general anesthesia \\ - Tranexamic acid \\ - Pre-operative Cefazolin 2-3g (Clindamycin $900 \mathrm{mg}$ if allergic to cephalosporins) \\ - Positioning \\ - Radiolucent specialized shoulder beach chair sat up to $45-60^{\circ}$ \\ - Arm positioner \\ o C-arm from head of bed \\ - Implants \\ ○ Reverse shoulder arthroplasty system of choice \\ - Fracture stem or standard stem with ingrowth/ongrowth capability \\ - Heavy gauge (\#2 and \#5) non-absorbable braided suture \\ - Cement available \\ - Additional \\ - Humeral head autogenous bone graft \\ - Shoulder retractors (Fakudda, Darrah, Bankart, Deltoid) \\ - Bone saw, osteotomes, drill bits \\ - Dilute betadine wash, antibiotic powder
}

Fig. 3 Preoperative planning steps for treatment of proximal humerus fracture with reverse shoulder arthroplasty

baseplate is inserted, and we place a 36-mm glenosphere for women and $40 \mathrm{~mm}$ for men. Glenosphere offset is debated and outside the scope of this article.

The humerus is exposed with 2 blunt medial and lateral Hohmann retractors, and a plastic retractor anterior to the glenosphere. Usually no humeral cut is necessary, and there is often a read medially suggesting the native calcar which can be used to set the stem height. Little reaming and sensible broaching is necessary and should only be done until the subtlest of cortical chatter is appreciated. The final broach is placed, and trial polyethylene of varying thicknesses are utilized to confirm appropriate balance.

After confirming reasonable trial balance, the final stem is implanted. Our goal is good press-fit fixation proximally. Since most patients undergoing this procedure lack good metaphyseal bone, it is our practice to size down when between sizes and utilize head autograft for impaction grafting at final stem insertion. This adds to the bone stock and avoids hoop stresses and stress concentration. If this is not obtainable, a hybrid technique can be used to obtain good distal press-fit fixation and conservative proximal cementation. Prior to placing the implant, two, $2.5-\mathrm{mm}$ drill holes are placed about $1 \mathrm{~cm}$ apart just above the pectoralis tendon on either side of the bicipital groove. Two no. 2 permanent braided sutures are passed in and then out each hole, one headed medially for later lesser tuberosity vertical fixation, and one headed laterally for the greater tuberosity. These sutures are passed around the stem of the component as it is inserted to avoid pullout (Fig. 7e). Once the final stem is inserted, the humeral tray and polyethylene is trialed, and final implants are selected based on stability, tension, and motion. The greater and
Fig. 4 Intraoperative technical steps for treatment of proximal humerus fracture with reverse shoulder arthroplasty

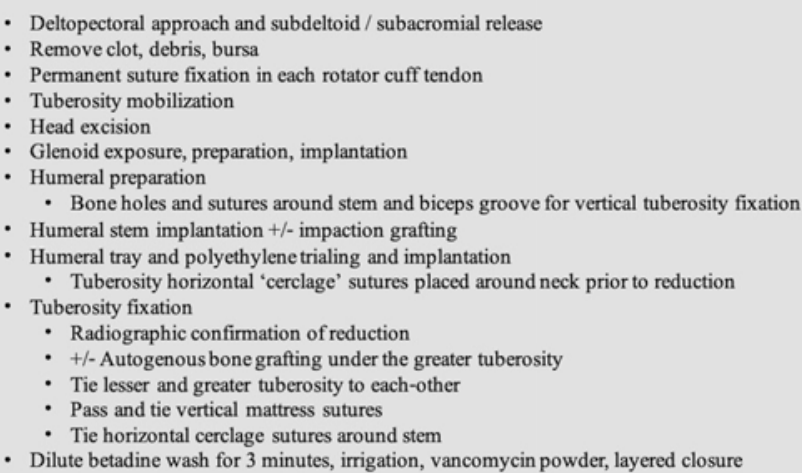




\section{Reverse Shoulder Arthroplasty for Proximal Humerus Fracture: Postoperative Protocol}

- Stat Grashey view shoulder radiograph in post-anesthesia care unit

- Observation / 24-hour admission for IV antibiotics, physical and occupational therapy

- Scheduled Acetaminophen, judicious narcotics

- Calcium and Vitamin D supplementation

- Outpatient bone health fragility workup and treatment

- Physical therapy

o Core conditioning, gait training

o Non-weight bearing for 12 weeks or until tuberosity healing

o Begin formal therapy for passive range of motion (ROM) at 2 weeks

o Advance to active assist ROM at 6 weeks

o Advance to active ROM and strengthening if needed after 12 weeks once ROM maximized

Fig. 5 Postoperative protocol for reverse shoulder arthroplasty

lesser tuberosity cerclage sutures, which have already been placed, are passed around the neck (under the humeral tray) prior to reduction (Fig. $7 \mathrm{f}$ ).

Next, a large piece of humeral head cancellous autograft is harvested and placed between the greater tuberosity and the stem's porous coating [93]. The lesser and greater tuberosities are approximated together using several of the no. 2 permanent braided sutures and a needle driver (subscapularis and teres minor stitches are approximated). When tension is unacceptable, the lesser tuberosity may be
Fig. 6 Initial injury AP (a), scapular-Y (b), and axillary (c) radiographs of a highly displaced 3-part fracture of the left proximal humerus with appreciable osteopenia. Postoperative AP (a), scapular-Y (b) radiographs following reverse shoulder arthroplasty for fracture

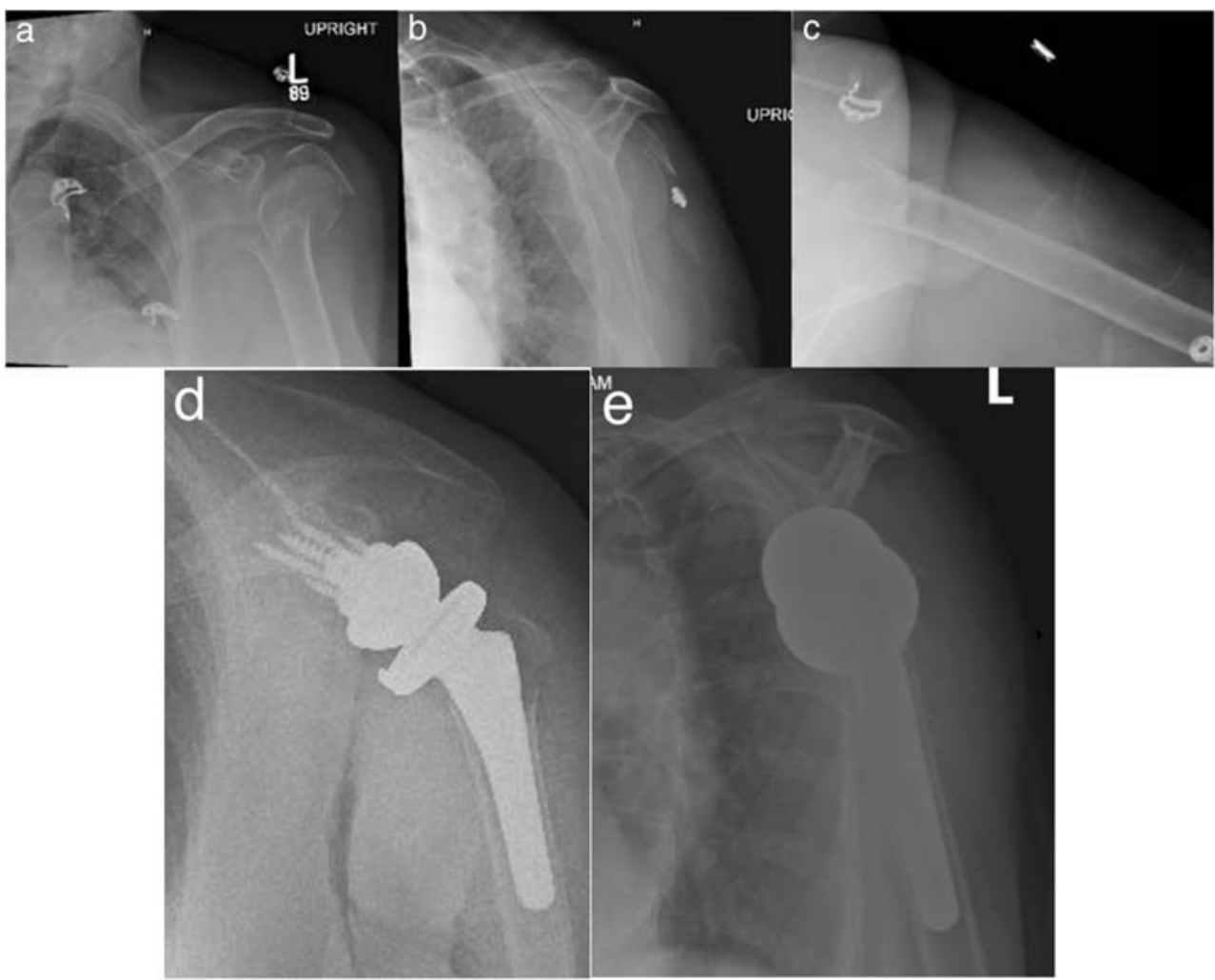



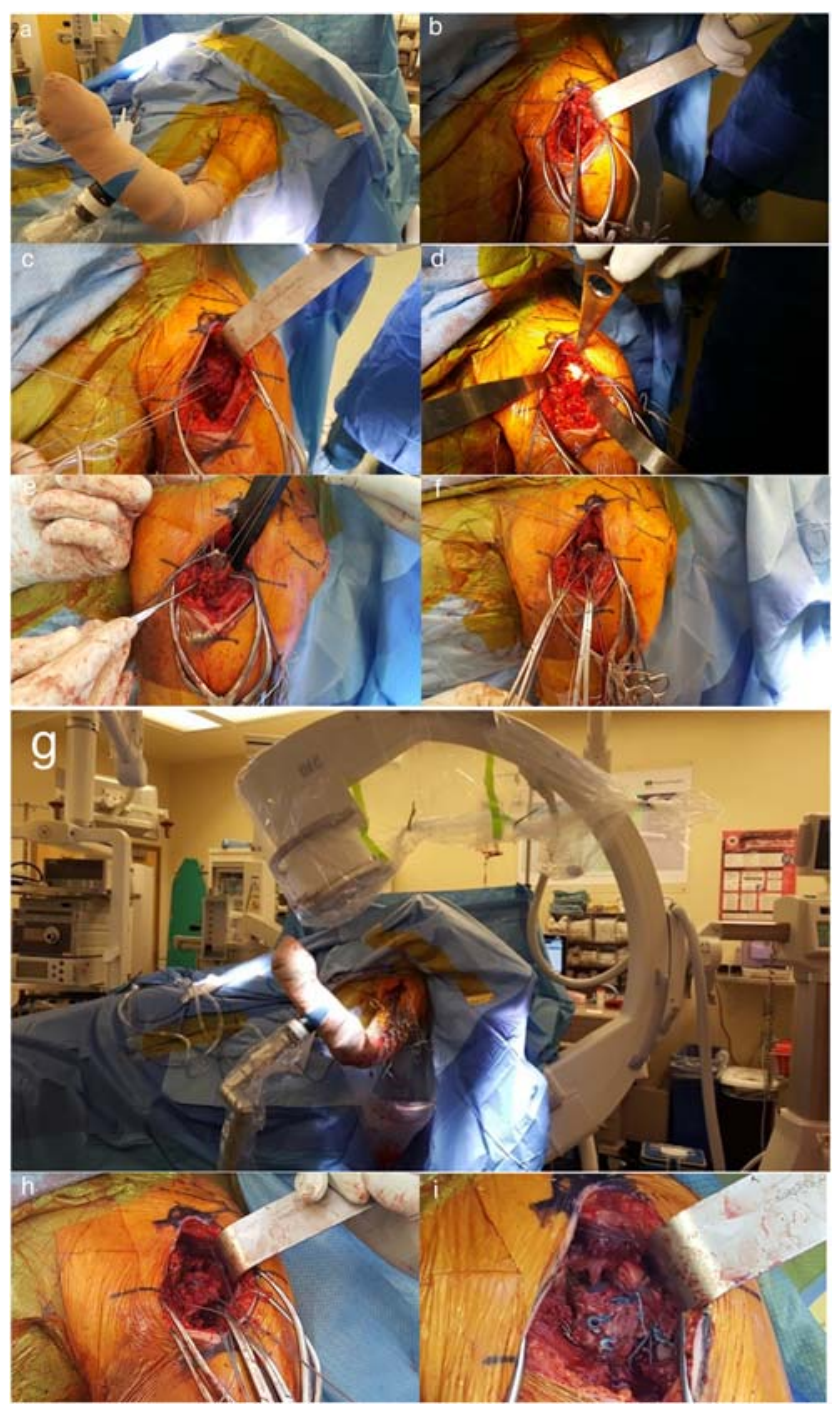

excised and the subscapularis released [92, 94]. Fluoroscopy confirms tuberosity alignment (Fig. 7g). These sutures are then tied (Fig. 7h). Next, the vertical stitches are passed through the subscapularis and infraspinatus to combat superior migration similar to the technique described by Formaini et al. [95]. The cerclage sutures are securely tied down to "bear hug" the tuberosities to the stem (Fig. 7i). With this technique, we find fracture stems to be superfluous. Contemporary stems fill more volume and have acceptable ingrowth potential, and mechanically, this suture technique hugs around the construct, rather than pulleying the tuberosity down as is traditional for fracture stems. The remainder of the sutures can be incorporated or discarded as seen fit. Remaining graft can be placed under the tuberosities as needed.

The wound is soaked in a dilute betadine solution for $3 \mathrm{~min}$ and then copiously irrigated to minimize infection risk. Prior
Fig. 7 Intraoperative photographs and technique notes for RSA: initial beach chair setup with arm positioner (a); deltopectoral exposure to include release of anterior $1 / 2$ of supraspinatus (which can be antagonistic to a tension free, anatomic reduction) (b); tagging the rotator cuff tendons with four no. 2 braided nonabsorbable sutures placed from anterior to posterior in the supraspinatus, infraspinatus, and teres minor. A no. 5 braided nonabsorbable suture is placed through the teres minor and around the posterior greater tuberosity to be cerclaged around the stem of the implant for tuberosity reduction (c); glenoid exposure with Bankart retractors anteroinferior and posteroinferior. If necessary, a Hohman is placed short of the spinoglenoid notch superiorly (d); two no. 2 braided nonabsorbable sutures are placed in and out of two drill holes on either side of the bicipital groove and around the stem. These vertical stitches are later passed through the infraspinatus and subscapularis to prevent superior escape (e); the no.5 braided nonabsorbable suture previously passed through the teres minor (b) is passed around the stem of the implant to eventually "bear hug" the tuberosities down to the porous coated portion of the implant (f). After the no. 2 stitches from the subscapularis and teres minor are provisionally tensioned for trial reduction, intraoperative fluoroscopy is obtained to check implant positioning and tuberosity reduction by rolling over from the head of the bed for a Grashey view (g). The rotator cuff sutures are sequentially tied starting with the subscapularis to teres minor, conforming on imaging that the tuberosity reduction is satisfactory (h). Finally, the vertical and cerclage sutures are tied to complete the construct (i)

to closure, $1 \mathrm{~g}$ of vancomycin powder is divided between each of the layers. For RSA, we close the deltopectoral interval to provide a biological layer between the components and the skin followed by dermal and skin closure. The patient is placed into a simple sling (please see Fig. 4 for key intraoperative technical steps; please see Fig. 5 for postoperative protocol).

\section{Case Example}

This is a case of a 84-year-old right-hand dominant female with past medical history significant for hypertension and essential tremor who fell secondary to a syncopal event while visiting her husband at his transitional care facility. She presented to our level-I trauma center with isolated left shoulder pain. Prior to the fall, she lived at home independently (see Fig. 6a-c for preoperative radiographs; see Fig. 7 for intraoperative photographs and technique notes; see Fig. $6 \mathrm{~d}$, e for postoperative radiographs).

\section{Conclusions}

Reverse shoulder arthroplasty is increasing in use for proximal humerus fractures as hemiarthroplasty decreases and open reduction internal fixation rates remain stable. Reverse shoulder arthroplasty is the preferred treatment for 3-part, 4-part, and head-splitting fractures of the proximal humerus in physiologically older individuals. Functional outcome scores, range of motion, and satisfaction scores are superior when compared to other surgical treatments. Long-term follow-up studies are 
necessary to determine if these results will continue with time. While reported complication rates of RSA may exceed that of ORIF or hemiarthroplasty, the revision and reoperation rates are lower. In particular, the revision and reoperation rates are significantly lower than in hemiarthroplasty with the benefit of significantly improved functional outcomes reported, especially in elderly. The patient and surgeon should be aware that while function will not be "normal," it is generally adequate for this low-demand patient population.

\section{Compliance with Ethical Standards}

Conflict of Interest Brandon Kelly, MD and Chad Myeroff, MD declare that they have no conflicts of interest.

Human and Animal Rights and Informed Consent This article does not contain any studies with human or animal subjects performed by any of the authors.

\section{References}

Papers of particular interest, published recently, have been highlighted as:

- Of importance

•• Of major importance

1. Hasty EK, Jernigan EW, Soo A, Varkey DT, Kamath GV. Trends in surgical management and costs for operative treatment of proximal humerus fractures in the elderly. Orthopedics. 2017;40(4):641-7.

2. Bell J, Leung BC, Spratt KF, Koval KJ, Weinstein JD, Goodman DC, et al. Humeral fractures in the elderly. J Bone Jt Surg. 2011;93A(2):121-31.

3. Clement ND, Duckworth AD, Mcqueen MM. The outcome of proximal humeral fractures in the elderly predictors of mortality and function. Bone Jt J. 2014;96-B(7):970-7.

4. Court-Brown CM, Caesar B. Epidemiology of adult fractures: a review. Injury. 2006;37:691-7.

5. Han RJ, Sing DC, Feeley BT, Ma CB, Zhang AL. Proximal humerus fragility fractures: recent trends in nonoperative and operative treatment in the Medicare population. J Shoulder Elb Surg. 2016;25(2):256-61. Available from:. https://doi.org/10.1016/j.jse. 2015.07.015

6. Kim SH, Szabo RM, Marder RA. Epidemiology of humerus fractures in the United States: nationwide emergency department sample, 2008. Arthritis Care Res. 2012;64(3):407-14.

7. Palvanen M, Kannus P, Niemi S, Parkkari J. Update in the epidemiology of proximal humeral fractures. Clin Orthop Relat Res. 2006;442:87-92.

8. Rajaee SS, Yalamanchilli D, Noori N, Debbi A, Mirocha J, Lin CA, et al. Increasing use of reverse total shoulder arthroplasty for proximal humerus fractures in elderly patients. Orthopedics. 2017;40(6): 982-9.

9. Schairer WW, Nwachukwu BU, Lyman S, Gulotta LV. Arthroplasty treatment of proximal humerus fractures: 14-year trends in the United States. Phys Sportsmed. 2017;45(2):92-6.

10. Court-brown CM, Duckworth AD, Clement ND, Mcqueen MM. Fractures in older adults. A view of the future. Injury. 2018;49(12): 2161-6. Available from. https://doi.org/10.1016/j.injury.2018.11. 009.
11. Myeroff CM, Anderson JP, Sveom DS, Switzer JA. Predictors of mortality in elder patients with proximal humeral fracture. Geriatr Orthop Surg Rehabil. 2017;9:1-6.

12. Dillon MT, Prentice HA, Burfeind WE, Chan PH, Navarro RA. The increasing role of reverse total shoulder arthroplasty in the treatment of proximal humerus fractures. Injury. 2019;50(3):1-5. https://doi.org/10.1016/j.injury.2019.01.03 Epidepmiological look at the increase in RSA and the decrease in hemiarthroplasty for proximal humerus fracture.

13. Kim SH, Wise BL, Zhang Y, Szabo RM. Increasing incidence of shoulder arthroplasty in the United States. J Bone Jt Surg - Ser A. 2011;93(24):2249-54.

14. Rosas S, Law TY, Kurowicki J, Formaini N, Kalandiak SP, Levy JC. Trends in surgical management of proximal humeral fractures in the Medicare population: a nationwide study of records from 2009 to 2012. J Shoulder Elb Surg. 2016;25(4):608-13. Available from:. https://doi.org/10.1016/j.jse.2015.08.011.

15. Schairer WW, Nwachukwu BU, Lyman S, Craig EV, Gulotta LV. Reverse shoulder arthroplasty versus hemiarthroplasty for treatment of proximal humerus fractures. J Shoulder Elb Surg. 2015;24(10): 1560-6. Available from:. https://doi.org/10.1016/j.jse.2015.03.018.

16. Rasmussen S, Hvass I, Dalsgaard J, Christensen BS, Holstad E. Displaced proximal humeral fractures: results of conservative treatment. Injury. 1992;23(1):41-3.

17. Zyto K. Non-operative treatment of the proximal humerus of comminuted fractures in elderly patients. Injury. 1998;29(5):349-52.

18. Foruria AM, De Gracia MM, Larson DR, Munuera L, SanchezSotelo J. The pattern of the fracture and displacement of the fragments predict the outcome in proximal humeral fractures. J Bone Jt Surg [Br]. 2005;93-B(3):378-86.

19. Court-Brown CM, Garg A, Mcqueen MM. The translated two-part fracture of the proximal humerus: epidemiology and outcome in the older patient. J Bone Jt Surg [Br]. 2001;83(6):799-804.

20. Court-Brown CM, Cattermole H, Mcqueen MM. Impacted valgus fractures (B1.1) of the proximal humerus. Bone Jt J. 2002;84-B(4): 504-8.

21. Iyengar JJ, Devcic Z, Sproul RC, Feeley BT. Nonoperative treatment of proximal humerus fractures: a systematic review. J Orthop Trauma. 2011;25(10):612-7.

22. Platzer P, Thalhammer G, Oberleitner G, Kutscha-lissberg F. Displaced fractures of the greater tuberosity: a comparison of operative and nonoperative treatment. J Trauma - Inj Infect Crit Care. 2004;65(4):843-8.

23. Rangan A, Handoll H, Brealey S, Jefferson L, Keding A, Martin $\mathrm{BC}$, et al. Surgical vs nonsurgical treatment of adults with displaced fractures of the proximal humerus: the PROFHER randomized clinical trial. JAMA - J Am Med Assoc. 2015;313(10):1037-47.

24.• Handoll HH, Keding A, Corbacho B, Brealey SD, Hewitt C, Rangan A, et al. Five-year follow-up results of the PROFHER trial comparing operative and non-operative treatment of adults with a displaced fracture of the proximal humerus. J Bone Jt Surg [Br]. 2017;99-B(3):383-92 Follow-up to the PROFHER trial. While results are controversial due to significant selection bias, as discussed in the manuscript, the follow up of a large RCT still provides meaningful longer-term information on operatively vs. nonoperatively treated proximal humerus fractures.

25. Brorson S. Management of fractures of the humerus in Ancient Egypt, Greece, and Rome. Clin Orthop Relat Res. 2009;467(7): 1907-14.

26. Brorson S. Management of proximal humeral fractures in the nineteenth century. Clin Orthop Relat Res. 2011;469(4):1197-206.

27. Flatow EL, Harrison AK. A history of reverse total shoulder arthroplasty. Clin Orthop Relat Res. 2011;469(9):2432-9.

28. Neer CS. Articular replacement for the humeral head. J Bone Jt Surg. 1955;37-A:215-28. 
29. Neer CS. Displaced proximal humeral fractures. Part 1. Classification and evaluation. J Bone Jt Surg. 1970;52-A:1077-89.

30. Neer CS. Displaced proximal humerus fractures. Part 2. Treatment of the three-part and four-part displacement. J Bone Jt Surg. 1970;52-A:1090-103.

31. Esser RD. Open reduction and internal fixation of three- and fourpart fractures of the proximal humerus. Clin Orthop Relat Res. 1994;299:244-51.

32. Moda SK, Chadha NS, Sangway SS, Khurana DK, Dahiya AS, Siwach RC. Open reduction and fixation of proximal humeral fractures and fractures-dislocations. J Bone Jt Surg [Br]. 1990;72-B: 1050-2.

33. Sehr JR, Szabo RM. Semitubular blade plate for fixation in the proximal humerus. J Orthop Trauma. 1989;2(4):327-32.

34. Zyto K, Ahrengart L, Sperber A, Tornkvist H. Treatment of displaced proximal humeral fractures in elderly patients. J Bone Jt Surg [Br]. 1997;79-B(3):412-7.

35. Brunner F, Sommer C, Bahrs C, Heuwinkel R, Hafner C, Rillmann $\mathrm{P}$, et al. Open reduction and internal fixation of proximal humerus fractures using a proximal humeral locked plate: a prospective multicenter analysis. J Orthop Trauma. 2009;23(3):163-72.

36. Charalambous CP, Siddique I, Valluripalli K, Kovacevic M, Panose $\mathrm{P}$, Srinivasan M, et al. Proximal humeral internal locking system (PHILOS) for the treatment of proximal humeral fractures. Arch Orthop Trauma Surg. 2007;127:205-10.

37. Fankhauser F, Boldin C, Schippinger G, Haunschmid C, Szyszkowitz R. A new locking plate for unstable fractures of the proximal humerus. Clin Orthop Relat Res. 2005;430:176-81.

38. Jost B, Spross C, Grehn H, Gerber C. Locking plate fixation of fractures of the proximal humerus: analysis of complications, revision strategies and outcome. J Shoulder Elb Surg. 2013;22(4):5429. Available from:. https://doi.org/10.1016/j.jse.2012.06.008.

39. Koukakis A, Apostolou C, Taneja T, Korres DS, Amini A. Fixation of proximal humerus fractures using the PHILOS plate: early experience. Clin Orthop Relat Res. 2006;442:115-20.

40. Olerud P, Ahrengart L, Ponzer S, Saving J, Tidermark J. Internal fixation versus nonoperative treatment of displaced 3-part proximal humeral fractures in elderly patients: a randomized controlled trial. J Shoulder Elb Surg. 2011;20(5):747-55. Available from:. https:// doi.org/10.1016/j.jse.2010.12.018.

41. Owsley KC, Gorczyca JT. Displacement/screw cutout after open reduction and locked plate fixation of humeral fractures. J Bone Jt Surg. 2008;90-A(2):233-40.

42. Thanasas C, Kontakis G, Angoules A, Limb D, Orth F, Giannoudis P. Treatment of proximal humerus fractures with locking plates: a systematic review. J Shoulder Elb Surg. 2009;18(6):837-44. Available from:. https://doi.org/10.1016/j.jse.2009.06.004.

43. Gardner MJ, Weil Y, Barker JU, Kelly BT, Helfet DL, Lorich DG. The importance of medial support in locked plating of proximal humerus fractures. J Orthop Trauma. 2007;21(3):185-91.

44. Solberg BD, Moon CN, Franco DP, Paiement GD. Locked plating of 3-and 4-part proximal humerus fractures in older patients: the effect of initial fracture pattern on outcome. J Orthop Trauma. 2009;23(2):113-9.

45. Namdari S, Lipman AJ, Ricchetti ET, Tjoumakaris FP, Russell Huffman G, Mehta S. Fixation strategies to prevent screw cut-out and malreduction in proximal humeral fracture fixation. Clin Orthop Surg. 2012;4(4):321-4.

46. Arvesen JE, Gill SW, Sinatra PM, Eng M, Bledsoe G, Kaar SG. Biomechanical contribution of tension-reducing rotator cuff sutures in 3-part proximal humerus fractures. J Orthop Trauma. 2016;30(8): e262-6.

47. Haasters F, Siebenbürger G, Helfen T, Daferner M, Böcker W, Ockert B. Complications of locked plating for proximal humeral fractures - are we getting any better ? J Shoulder Elb Surg. 2016;25(10):e295-303. Available from:. https://doi.org/10.1016/j. jse.2016.02.015.

48. Hertel R, Hempfing A, Stiehler M, Leunig M. Predictors of humeral head ischemia after intracapsular fracture of the proximal humerus. J Shoulder Elb Surg. 2004;13(4):427-33.

49. Campochiaro G, Rebuzzi M, Baudi P, Catani F. Complex proximal humerus fractures: Hertel's criteria reliability to predict head necrosis. Musculoskelet Surg. 2015;99(Suppl 1):9-15. Available from:. https://doi.org/10.1007/s12306-015-0358-z.

50. Edelson G, Safuri H, Salami J, Vigder F, Militianu D. Natural history of complex fractures of the proximal humerus using a threedimensional classification system. J Shoulder Elb Surg. 2008;17(3): 399-409.

51. Zyto K, Wallace A, Frostick S, Preston B. Outcome after hemiarthroplasty for three- and four-part fractures of the proximal humerus. J Shoulder Elb Surg. 1998;7(2):85-9.

52. Antuna SA, Sperling JW, Cofield RH, De Asturias P. Shoulder hemiarthroplasty for acute fractures of the proximal humerus: a minimum five-year follow-up. J Shoulder Elb Surg. 2008;17(2): 202-9.

53. Boons HW, Goosen JH, Van Grinsven S, Van Susante JL, Van Loon CJ. Hemiarthroplasty for humeral four-part fractures for patients 65 years and older. Clin Orthop Relat Res. 2012;470(12):3483-91.

54. Dimakopoulos P, Potamitis N, Lambiris E. Hemiarthroplasty in the treatment of comminuted intraarticular fractures of the proximal Hhumerus. Clin Orthop Relat Res. 1997;341:7-11.

55. Sowa B, Thierjung H, Bülhoff M, Loew M, Zeifang F, Bruckner T, et al. Functional results of hemi- and total shoulder arthroplasty according to diagnosis and patient age at surgery. Acta Orthop. 2017;88(3):310-4.

56. Boileau P, Krishnan SG, Tinsi L, Walch G, Coste JS, Mole D. Tuberosity malposition and migration: reasons for poor outcomes after hemiarthroplasty for displaced fractures of the proximal humerus. J Shoulder Elb Surg. 2002;11(5):401-11.

$57 . \bullet$ Hacket DJ, Hsu JE, Matsen FA. Primary shoulder hemiarthroplasty: what can be learned from 359 cases that were surgically revised. Clin Orthop Relat Res. 2018;476(5):1031-40 Hemiarthroplasty is technically challenging and few patients fit narrow indications. If any question of durability of rotator cuff or reconstructability of proximal humerus fracture RSA is viable option.

58. Dezfuli B, King JJ, Farmer KW, Struk AM, Wright TW. Outcomes of reverse total shoulder arthroplasty as primary versus revision procedure for proximal humerus fractures. J Shoulder Elb Surg. 2016;25(7):1133-7. Available from:. https://doi.org/10.1016/j.jse. 2015.12.002.

59. Grubhofer F, Wieser K, Meyer DC, Catanzaro S, Beeler S, Rieder $\mathrm{U}$, et al. Reverse total shoulder arthroplsty for acute head-splitting, 3- and 4-part fractures of the proximal humerus in the elderly. J Shoulder Elb Surg. 2016;25:1690-8.

60.• Wright JO, Ho A, Kalma J, Koueiter D, Esterle J, Marcantonio D, et al. Uncemented reverse total shoulder arthroplasty as initial treatment for comminuted proximal humerus fractures. J Orthop Trauma. 2019;33(7):1 Available from: http://insights.ovid.com/ crossref?an=00005131-900000000-98495.

61. Shannon SF, Wagner ER, Houdek MT, Iii WWC, Sánchez-sotelo J. Reverse shoulder arthroplasty for proximal humeral fractures: outcomes comparing primary reverse arthroplasty for fracture versus reverse arthroplasty after failed osteosynthesis. J Shoulder Elb Surg. 2016;25(10):1655-60. Available from:. https://doi.org/10.1016/j. jse.2016.02.012.

62. Wolfensperger F, Grüninger P, Dietrich M, Völlink M, Benninger E, Schläppi M, et al. Reverse shoulder arthroplasty for complex fractures of the proximal humerus in elderly patients: impact on the level of independency, early function, and pain medication. J Shoulder Elb Surg. 2017;26(8):1462-8. https://doi.org/10.1016/j. jse. 2017.01 .021 Demonstrated high rate of return to 
independence following RSA for proximal humerus fracture within 1 year postoperatively.

63. Bufquin T, Hersan A, Hubert L, Massin P. Reverse shoulder arthroplasty for the treatment of three- and four-part fractures of the proximal humerus in the elderly. J Bone Jt Surg [Br]. 2007;89-B(4):516-20.

64. Klein M, Juschka M, Hinkenjann B, Scherger B, Ostermann PAW. Treatment of comminuted fractures of the proximal humerus in elderly patients with the Delta III reverse shoulder prosthesis. J Orthop Trauma. 2008;22(10):698-704.

65. Lenarz C, Shishani Y, Mccrum C, Do RJN, Edwards TB, Gobezie $\mathrm{R}$. Is reverse shoulder arthroplasty appropriate for the treatment of fractures in the older patient? Clin Orthop Relat Res. 2011;469(12): 3324-31.

66. Roberson TA, Granade CM, Hunt Q, Griscom JT, Adams KJ, Momaya AM, et al. Nonoperative management versus reverse shoulder arthroplasty for treatment of 3- and 4-part proximal humeral fractures in older adults. J Shoulder Elb Surg. 2016;26(6): 1017-22. Available from:. https://doi.org/10.1016/j.jse.2016.10. 013.

67.• Sebastia-Forcada E, Lizaur-Utrilla A, Cebrian-Gomez R, MirallesMuñoz FA, Lopez-Prats FA. Outcomes of reverse total shoulder arthroplasty for proximal humeral fractures: primary arthroplasty versus secondary arthroplasty after failed proximal humeral locking plate fixation. J Orthop Trauma. 2017;31(8):236-40 Better postoperative functional scores, ROM, complication, and revision rate for primary vs. secondary RSA.

68. Seidl A, Sholder D, Warrender W, Livesey M, Jr GW, Abboud J, et al. Early versus late reverse shoulder arthroplasty for proximal humerus fractures: does it matter? Arch Bone Jt Surg. 2017;5(4): 213-20.

69.• Torchia MT, Austin DC, Cozzolino N, Jacobowitz L, Bell J. Acute versus delayed reverse total shoulder arthroplasty for the treatment of proximal humeral fractures in the elderly population: a systematic review and meta-analysis. J Shoulder Elb Surg. 2019;28(4): 765-73. https://doi.org/10.1016/j.jse.2018.10.004 Meta-analysis and systematic review comparing acute versus delayed RSA demonstrating no significant outcome differences in timing.

70.• Austin DC, Torchia MT, Cozzolino NH, Jacobowitz LE, Bell J. Decreased reoperations and improved outcomes with reverse total shoulder arthroplasty in comparison to hemiarthroplasty for geriatric proximal humerus fractures: a systematic review and meta-analysis. J Orthop Trauma. 2019;33(1):49-57 Meta-analysis and systematic review comparing RSA and hemiarthroplasty showed RSA significantly outperformed hemirathroplasty for proximal humerus fracture treatment.

71. Shukla DR, Mcanany S, Kim J, Overley S, Parsons BO. Hemiarthroplasty versus reverse shoulder arthroplasty for treatment of proximal humeral fractures: a meta-analysis. J Shoulder Elb Surg. 2016;25(2):330-40. Available from:. https://doi.org/10. 1016/j.jse.2015.08.030

72. Ferrel JR, Trinh TQ, Fischer RA. Reverse total shoulder arthroplasty versus hemiarthroplasty for proximal humeral fractures: a systematic review. J Orthop Trauma. 2015;29(1):60-8.

73.• Gallinet D, Ohl X, Decroocq L, Dib C, Valenti P, Boileau P, et al. Is reverse total shoulder arthroplasty more effective than hemiarthroplasty for treating displaced proximal humerus fractures in older adults? A systematic review and meta-analysis. Orthop Traumatol Surg Res. 2018;104(6):759-66. https://doi.org/10. 1016/j.otsr.2018.04.025 RSA patients had better clinical outcome scores and forward flexion postoperatively compared to hemiarthroplasty patients who had better internal and external rotation postoperatively.

74. Namdari S, Jg H, Baldwin K. Comparison of hemiarthroplasty and reverse arthroplasty for treatment of proximal humeral fractures: a systematic review. J Bone Jt Surg. 2013;95-A(18):1701-8.
75. Bonnevialle N, Tournier C, Clavert P, Ohl X, Sirveaux F, Saragaglia D. Hemiarthroplasty versus reverse shoulder arthroplasty in 4-part displaced fractures of the proximal humerus: multicenter retrospective study. Orthop Traumatol Surg Res. 2016;102(2016):569-73.

76. Boyle MJ, Youn S, Frampton CMA, Ball CM. Functional outcomes of reverse shoulder arthroplasty compared with hemiarthroplasty for acute proximal humeral fractures. J Shoulder Elb Surg. 2013;22(1):32-7. Available from:. https://doi.org/10.1016/j.jse. 2012.03.006.

77. Chalmers PN, Iii WS, Mall NA, Gupta AK, Rahman Z, Enriquez D, et al. Reverse total shoulder arthroplasty for acute proximal humeral fracture: comparison to open reduction - internal fixation and hemiarthroplasty. J Shoulder Elb Surg. 2014;23(2):197-204. Available from:. https://doi.org/10.1016/j.jse.2013.07.044.

78. Cuff DJ, Pupello DR. Comparison of hemiarthroplasty and reverse shoulder arthroplasty for the treatment of proximal humeral fractures in elderly patients. J Bone Jt Surg - Ser A. 2013;95(22):2050 5.

79. Garrigues GE, Johnston PS, Pepe MD, Tucker BS, Ramsey ML, Austin LS. Hemiarthroplasty versus reverse total shoulder arthroplasty for acute proximal humerus fractures in elderly patients. Orthopedics. 2012;35(5):703-8.

80. Van Der Merwe M, Boyle MJ, Frampton CMA, Ball CM. Reverse shoulder arthroplasty compared with hemiarthroplasty in the treatment of acute proximal humeral fractures. J Shoulder Elb Surg. 2017;26(9):1539-45. Available from:. https://doi.org/10.1016/j. jse.2017.02.005.

81. Reuther F, Petermann M, Stangl R. Reverse shoulder arthroplasty in acute fractures of the proximal humerus: does tuberosity healing improve clinical outcomes. J Orthop Trauma. 2019;33(2):46-51 Case series demonstrating no significant difference for functional scores or ROM for healed vs. unhealed greater tuberosity in RSA.

82. Jain NP, Mannan SS, Dharmarajan R, Rangan A. Tuberosity healing after reverse shoulder arthroplasty for complex proximal humeral fractures in elderly patients - does it improve outcomes? A systematic review and meta-analysis. J Shoulder Elb Surg. 2019;28(3):e78-91 Systematic review and meta-analysis showing RSA patients with healed greater tuberosity had better ROM and functional outcome scores.

83. Simovitch RW, Roche CP, Jones RB, Routman HD, Marczuk Y, Wright TW, et al. Effect of tuberosity healing on clinical outcomes in elderly patients treated with a reverse shoulder arthroplasty for 3and 4-part proximal humerus fractures. J Orthop Trauma. 2019;33(2):E39-45 Greater tuberosity healing in RSA results in better external rotation postoperatively than if it does not radiographically heal.

84. Torrens C, Alentorn-geli E, Mingo F, Gamba C, Santana F. Reverse shoulder arthroplasty for the treatment of acute complex proximal humeral fractures: influence of greater tuberosity healing on the functional outcomes. J Orthop Surg. 2018;26(1):1-7 No significant differences among patients who undergo RSA and have tuberosity healing and those that do not.

85. Cvetanovich GL, Chalmers PN, Verma NN, Nicholson GP, Romeo AA. Open reduction internal fixation has fewer short-term complications than shoulder arthroplasty for proximal humeral fractures. J Shoulder Elb Surg. 2016;25(4):624-631.e3. Available from:. https://doi.org/10.1016/j.jse.2015.09.011.

86. Zhang AL, Schairer WW, Feeley BT. Hospital readmissions after surgical treatment of proximal humerus fractures: is arthroplasty safer than open reduction internal fixation? Clin Orthop Relat Res. 2014;472(8):2317-24.

87. Gupta AK, Harris JD, Erickson BJ, Abrams GD, Bruce B, Mccormick F, et al. Surgical management of complex proximal humerus fractures - a systematic review of 92 studies including 4500 patients. J Orthop Trauma. 2015;29(1):54-9. 
88. Gallinet D, Cazeneuve JF, Boyer E, Menu G, Obert L, Ohl X, et al. Reverse shoulder arthroplasty for recent proximal humerus fractures: outcomes in 422 cases. Orthop Traumatol Surg Res. 2019;1-7. Available from: http://www.ncbi.nlm.nih.gov/pubmed/ 31279769. Revision rate for RSA after proximal humerus fracture is $\mathbf{5 \%}$ after $\mathbf{2 3 8}$ months.

89. Klug A, Wincheringer D, Harth J, Schmidt-horloh K, Hoffmann R, Gramlich Y, et al. Complications after surgical treatment of proximal humerus fractures in the elderly-an analysis of complication patterns and risk factors for reverse shoulder arthroplasty and angular-stable plating. J Shoulder Elb Surg. 2019;1-11. RSA revision rate is $5.1 \%$, which is lower than the $12.1 \%$ rate seen in ORIF patients with mean follow up 3.5 years.

90.• Bacle G, Nové-Josserand L, Garaud P, Walch G. Long-term outcomes of reverse total shoulder arthroplasty. J Bone Jt Surg. 2017;99(6):454-61 Available from: http://insights.ovid.com/ crossref?an $=00004623-201703150-00002$ - Long-term follow up study of RSA demonstrating $93 \%$ survival rate at 10 years.

91. Neer CS. Four-segment classification of proximal humerus fractures: purpose and reliable use. J Shoulder Elb Surg. 2002;11(4): e389-400.

92. Giles JW, Langohr GDG, Johnson JA, Athwal GS. The rotator cuff muscles are antagonists after reverse total shoulder arthroplasty. J
Shoulder Elb Surg. 2016;25(10):1592-600. Available from:. https://doi.org/10.1016/j.jse.2016.02.028.

93. Uzer G, Yildiz F, Batar S, Binlaksar R, Elmadag M, Kus G, et al. Does grafting of the tuberosities improve the functional outcomes of proximal humeral fractures treated with reverse shoulder arthroplasty? J Shoulder Elb Surg. 2017;26(1):36-41. Available from:. https://doi.org/10.1016/j.jse.2016.05.005.

94. Werner BC, Wong AC, Mahony GT, Craig EV, Dines DM, Warren $\mathrm{RF}$, et al. Clinical outcomes after reverse shoulder arthroplasty with and without subscapularis repair: the importance of considering glenosphere lateralization. J Am Acad Orthop Surg. 2018;26(5): e114-9.

95. Formaini NT, Everding NG, Levy JC, Rosas S. Tuberosity healing after reverse shoulder arthroplasty for acute proximal humerus fractures: the "black and tan" technique. J Shoulder Elb Surg. 2015;24(11):e299-306. Available from:. https://doi.org/10.1016/j. jse.2015.04.014.

Publisher's note Springer Nature remains neutral with regard to jurisdictional claims in published maps and institutional affiliations. 